\title{
A solution to the challenges of particle erosion and thermal cycle for PS-PVD 7YSZ thermal barrier coatings
}

\section{Xiaofeng Zhang ( $\sim$ zxf200808@126.com )}

Guangdong Institute of New Materials https://orcid.org/0000-0002-7321-9631

\section{Ming Li}

guang dong sheng ke xue yuan: Guangdong Academy of Sciences

\section{Yan Zhang}

Guangdong Academy of Sciences

\section{Ziqian Deng}

Guangdong Academy of Sciences

\section{Jiafeng Fan}

Guangdong Academy of Sciences

\section{Xueshi Zhuo}

Guangdong Academy of Sciences

\section{Juhang Yin}

Guangdong Academy of Sciences

\section{Shuangquan Guo}

Guangdong Academy of Sciences

Jie Mao

Guangdong Academy of Sciences

\section{Chunming Deng}

Guangdong Academy of Sciences

Cheng Lai

Guangdong Academy of Sciences

\section{Panpan Wang}

Changzhou Institute of Technology

Jianhui Lai

Guangdong Academy of Sciences

Changguang Deng

Guangdong Academy of Sciences

Junli Feng

Guangdong Academy of Sciences

Min Liu 
Guangdong Academy of Sciences

Kesong Zhou

Guangdong Academy of Sciences

\section{Research Article}

Keywords: PS-PVD, Thermal barrier coatings, Particle erosion resistance, Thermal cycle

Posted Date: March 18th, 2021

DOl: https://doi.org/10.21203/rs.3.rs-332060/v1

License: (c) (1) This work is licensed under a Creative Commons Attribution 4.0 International License. Read Full License 


\section{Abstract}

Advanced aero-engine is a key technique that is used all over the world, where many high-temperature components such as turbine blades and combustor, are made of $\mathrm{Ni} / \mathrm{Co} / \mathrm{Fe}$ based superalloys. However, they need high-temperature protection to avoid fast performance degradation. Generally, the superalloy high-temperature components are protected by thermal barrier coatings (TBCs) obtained via an atmospheric plasma spray (APS) and an electron beam-physical vapor deposition (EB-PVD). Here, a novel 3rd generation TBCs process using plasma spray-physical vapor deposition (PS-PVD) is presented, showing a more promising use than the traditional APS and EB-PVD. The PS-PVD feature uses evaporating ceramic powder, which results in the deposition of a feather-like columnar coating. This special microstructure showed good strain tolerance and non-line-of-sight (NLOS) deposition, giving great potential for application. In a working aero-engine, the high-temperature components face a serious environment, where foreign particle erosion is a great challenge and is the first barrier to the application of PS-PVD TBCs. As a solution, an Al-modification approach was proposed in this investigation. The results demonstrate that this approach can improve particle erosion resistance. Also, the thermal cycle performance had an apparent optimization.

\section{Highlights}

- After Al-modification, the particle erosion resistance of PS-PVD 7YSZ TBCs has apparent improvement.

- The Al-modified PS-PVD 7YSZ TBCs can reach 350 water quenching cycles at $1100{ }^{\circ} \mathrm{C}$.

- The interaction between plasma flame and substrate was investigated about velocity and temperature distribution.

\section{Introduction}

The aero-engine is known as the crown jewel in the industry. Highly safe, high-performance aero-engines are important for the realization of human air travel. As an advanced technology, the aero-engine has attracted much attention all over the world since 1903. Highly efficient power and a high thrust-weight ratio have always been the aim. To realize these targets, increasing the turbine inlet temperature (TIT) is a direct approach. However, those high-temperature superalloy components in the aero-engine cannot meet the requirements of an advanced engine, due to the relatively low melting point $\left(\sim 1150^{\circ} \mathrm{C}\right)^{1-4}$. Generally, the surface temperature of the turbine blades in a service environment $\left(\geq 1200^{\circ} \mathrm{C}\right)$ is much higher than its melting point, even with the high-efficiency gas-film cooling technology ${ }^{5-6}$. Considering this limitation, thermal barrier coatings (TBCs) were proposed to reduce the working temperature of the high-temperature components. After more than 60 years of research and development, the TBCs prepared by atmospheric plasma spray (APS) and electron beam-physical vapor deposition (EB-PVD) have been applied extensively in aeroengines ${ }^{7-8}$. The APS process has many advantages, such as low cost and high efficiency. ${ }^{9-10}$ The EB-PVD TBCs also have many merits, such as high strain tolerance and high bond 
strength. ${ }^{11-12}$ However, to prolong the TBCs lifetime, there are many challenges to overcome, such as foreign particle erosion, and frequent thermal cycle performance ${ }^{13-15}$.

The constant progress of the aero-engine TIT process as well as increasing pollution restrictions determine the development of heat-resistant coatings. The new deposition technique of plasma sprayphysical vapor deposition (PS-PVD) has a different deposition mechanism as compared with the traditional processes. The APS TBCs have a laminar structure obtained through splat deposition, which causes the challenges of low strain tolerance and low bond strength. ${ }^{16-17}$. The EB-PVD TBCs have a columnar structure obtained via vapor-deposited atoms, and they face the challenges of high cost and high thermal conductivity ${ }^{18-19}$. The PS-PVD process can avoid these limitations to some extent. In this investigation, the key feature of the PS-PVD process is the option of evaporating ceramic powders, which enables the deposition of a feather-like columnar ceramic coating ${ }^{20-22}$. The PS-PVD TBCs have many advantages, such as the uniform coating on irregularly shaped components, a high deposition efficiency,

and a low thermal conductivity ${ }^{23-24}$. However, the characteristic high porosity of PS-PVD TBCs hurts particle erosion performance ${ }^{25-26}$, which is the great challenge before application.

Facing this challenge, an Al-modification method was proposed for PS-PVD 7YSZ TBCs in this investigation. Through magnetron sputtering, appropriate thickness of Al film was deposited on TBCs surface. Subsequently, the Al-deposited TBCs were carried out with vacuum heat treatment. Then an a$\mathrm{Al}_{2} \mathrm{O}_{3}$ dense overlay will be in-situ synthesized through reaction between $\mathrm{Al}$ and $\mathrm{ZrO}_{2}$. This dense layer will provide a positive effect for TBCs. The main difference of Al-modification from traditional approaches is a- $\mathrm{Al}_{2} \mathrm{O}_{3}$ phase resulting from in-situ synthesis. Thus, this overlay has good bond with original 7YSZ TBCs. Possibility, Al-modification is an important approach to improve the performance of PS-PVD 7YSZ TBCs

\section{Experimental Section 2.1. TBCs Preparation}

The columnar 7YSZ ceramic coating with feather-like structure were prepared by PS-PVD facility (Oerlikon Metco) on NiCrAlY bond coating. The feedstock materials NiCrAlY powders (9624, Oerlikon Metco) and agglomerated 7YSZ powders (M6700, Oerlikon Metco) were used. And disks made of DZ125 superalloy (sample size: $\Phi 25.4 \times 5 \mathrm{~mm}$ ) were used as substrates. The spray parameters of NiCrAlY coating (net power of plasma torch $46 \mathrm{~kW}$, current $1650 \mathrm{~A}$, Ar 110 slpm, $\mathrm{H}_{2} 6$ splm, feed rate $20 \mathrm{~g} / \mathrm{min}$, chamber pressure $40 \mathrm{mbar}$ ) and 7YSZ coating (net power of plasma torch $57 \mathrm{~kW}$, current $2600 \mathrm{~A}, \mathrm{Ar} 35 \mathrm{slpm}$, He 60 slpm, feed rate $18 \mathrm{~g} / \mathrm{min}$, chamber pressure $1.5 \mathrm{mbar}$ ) were optimized based on previous investigation. To further improve their performance, the 7YSZ TBCs were deposited with Al film on their surface by magnetron sputtering. And then, the Al-deposited 7YSZ TBCs samples with different Al film thicknesses of 5,10 , and $20 \mu \mathrm{m}$ were carried out with vacuum heat treatment, forming Al-modified 7YSZ TBCs. During deposition, Al target (99.99\%) was used and the direct current, voltage, and pressure were set as 3 A, 150 
$\mathrm{V}$, and $5 \times 10^{-3} \mathrm{~Pa}$, respectively. And the Al-deposited TBCs samples were treated with a certain parameter $\left(608^{\circ} \mathrm{C}\right.$ for $1 \mathrm{~h}, 700^{\circ} \mathrm{C}$ for $1 \mathrm{~h}$, and $980^{\circ} \mathrm{C}$ for $2 \mathrm{~h}$ ). Above experiment process can be seen in the following supplementary video.

\subsection{Plasma flow simulation}

The plasma flow of the PS-PVD was equivalent to a quasi-equilibrium continuous medium, and its flow process was described by an N-S equation. Therefore, it is accurate to establish the plasma flow model by a CFD (Computational Fluid Dynamics) simulation. The internal and external flow field model of the spray gun was established by ANSYS FLUENT (Ansys 2020 R2, URL: //www.ansys.com/), which included consideration for the coupling effect of the internal and external flow field. To show the turbulent characteristics of the plasma flow, the SST-KW two-equation turbulence model was used during the process of the CFD calculations.

\subsection{TBCs characterization}

The microstructures of the as-sprayed and Al-modified 7YSZ TBCs were characterized by field emissionscanning electron microscope (FE-SEM, Nova-Nono430, FEI) and transmission electron microscopy (TEM, Titan Themis 200, FEI) assisted by focused ion beam (FIB, 450S, FEI) milling. The phase compositions of the as-sprayed and Al-modified TBCs were identified by X-ray diffraction (10-90 ${ }^{\circ}$, SmartLab, Rigaku, Japan). Also, the particle erosion resistances of the TBCs were evaluated by a scratch tester $(\mathrm{HH}-3000$, CAS, China). This is a dead-loaded machine where a separate scratch is made for each applied load. The load was continuously increased from 0 to $80 \mathrm{~N}$ with a rate of $100 \mathrm{~N} / \mathrm{m}$ and a scratch length of $4 \mathrm{~mm}$. The tester was fitted with friction coefficient monitoring equipment which was used as an on-line failure monitor. The particle erosion performance of both types of TBCs (sample size: $\Phi 25.4 \times 5 \mathrm{~mm}$ ) was carried out based on the GE standard E50TF121 (impingement angle $20^{\circ}$, distance $101.6 \mathrm{~mm}$, erosion media 240 grit) at room temperature. The thermal cycling properties of the as-sprayed and Al-modified PS-PVD 7YSZ TBCs were analyzed by water-quenching testing. The specimens (sample size: $\Phi 25.4 \times 5$ $\mathrm{mm}$ ) were heated at an evaluated temperature of $1100^{\circ} \mathrm{C}$ in a furnace for $10 \mathrm{~min}$ followed by direct water-quenching at room temperature for $5 \mathrm{~min}$.

\section{Results And Discussion}

\subsection{Challenges of PS-PVD 7YSZ TBCs}

A typical failure in TBCs can be seen in Fig. 1a (Turbo Fan Engine CFM56, Boeing 737). With fast development of aero-engine, the TIT will increase continually, which lead to requirements of high performance TBCs. And the progress of superalloy and TBCs had been summarized in Fig. 1b. For TBCs, APS, EB-PVD and PS-PVD are important preparation method. The APS TBCs have disadvantages of low strain tolerance and low bond strength. (Fig. 1c) ${ }^{16-17}$. The EB-PVD TBCs have disadvantages of high cost and high thermal conductivity (Fig. 1C) ${ }^{18-19}$. The PS-PVD has a different deposition mechanism as compared with the traditional processes, which can avoid these weaknesses to some extent. The core 
feature of PS-PVD process is the option of evaporating ceramic powders, which will obtain a feather-like columnar ceramic coating (Fig. 1C) ${ }^{23-24}$. However, the characteristic high porosity of PS-PVD TBCs is the great challenge before application.

Inherent weakness of high porosity for PS-PVD TBCs results from its high velocity and high concentration vapor deposition (Fig. 2a), which is different from EB-PVD ${ }^{27}$. The high velocity of the plasma flow and the high concentration of vapor particles in the PS-PVD process creates a non-line-of-sight (NLOS) deposition, which forms a feather-like columnar coating (Fig. 2b) ${ }^{23}$. However, a high concentration leads to a shadow effect created during the nucleation and growth of the vapor particles on the substrate, which is the biggest difference when compared with the EB-PVD process. Additionally, the size of the plasma flame is large, resulting in a large deposition area on the substrate. Figure $2 b$ shows that the feather-like columnar 7YSZ coating has a different sized gap from the bottom to the top area, where the columns are made of nano-sized grains. A dense coating at the bottom is also a columnar structure, but the gap is very small.

Previous investigations indicate that the promising feather-like columnar microstructure depends on a temperature gradient and the velocity gradient of a plasma flame ${ }^{27-29}$. During the PS-PVD spray, the plasma temperature (Fig. 2c) and velocity (Fig. 2d) distribution were modeled through a computational fluid dynamics (CFD) simulation. The gas flow rate at the inlet of the spray gun was $95 \mathrm{~L} / \mathrm{min}$, the boundary pressure of the outflow field was $150 \mathrm{~Pa}$, and a superalloy substrate was set at $1000 \mathrm{~mm}$ from the outlet of the spray gun. Figure $2 \mathrm{c}$ shows that when the plasma gases left the spray gun outlet, the temperature was still as high as $20,000{ }^{\circ} \mathrm{C}$. With an increase in the distance from the gun outlet, the plasma temperature dropped rapidly. The plasma temperature at the position of the substrate decreased to about $1400{ }^{\circ} \mathrm{C}$. As seen in Fig. $2 \mathrm{~d}$, when the plasma left the outlet of the plasma gun, it had a velocity of $7000 \mathrm{~m} / \mathrm{s}$. With the increase of the distance from the gun outlet, the plasma velocity dropped rapidly, to $300 \mathrm{~m} / \mathrm{s}$ when it reached the substrate $(1000 \mathrm{~mm})$.

\subsection{Solution for particle erosion resistance}

It is known that the service environment of TBCs (Fig. 3a) includes high temperatures, particle erosion, and CMAS corrosion ${ }^{1-4}$. Due to the high vapor particle concentration, the feather-like columnar 7YSZ coating had a high porosity. This feature led to a low thermal conductivity and high-stress tolerance ${ }^{30}$. However, this microstructure resulted in a negative effect on particle erosion resistance ${ }^{31}$. As a solution to the issue, an Al-modified approach was proposed (Fig. 3b) where an Al film was deposited on the featherlike columnar 7YSZ coating. After a vacuum heat treatment, the Al film infiltrated into the columnar coating and reacted with the 7YSZ coating, forming a dense $\mathrm{a}-\mathrm{Al}_{2} \mathrm{O}_{3}$ overlay. To optimize the process, $\mathrm{Al}$ films with different thicknesses $(5,10,20 \mu \mathrm{m})$ were deposited onto the TBCs surface. Figure $3 \mathrm{c}$ shows a cross-sectional microstructure evolution with the Al film before and after vacuum heat treatment. The 5 $\mu \mathrm{m}$ Al-modified TBCs were characterized by TEM (Fig. 3d), which shows the cross-sectional elemental analysis including HAADF (High Angle Annular Dark Field) image and Al, $\mathrm{O}$ and $\mathrm{Zr}$ mappings. The experimental results demonstrated that the microstructure of the deposited and Al-modified TBCs are in accordance with the schematic diagram in Fig. $3 b$. 
The Al-modification process aimed to improve particle erosion performance. Firstly, to characterize the erosion resistance, the as-sprayed and Al-modified TBCs were compared using scratch testing. Scratch micrographics of different TBCs with different-sized micro-cracks are shown in Figs. 4a-d, where the various positions $\mathrm{P} 1, \mathrm{P} 2$, and $\mathrm{P} 3$ corresponding to the initial position, middle position, and terminal position of the scratch path are presented. Using a scratch comparison method of the 3D surface profile, the as-sprayed TBCs had a depth of $72 \mu \mathrm{m}$, which was deeper than the 5, 10, and $20 \mu \mathrm{m}$ Al-modified $\operatorname{TBCs}(71,57$, and $56 \mu \mathrm{m})$. Moreover, the friction forces and friction coefficients of the as-sprayed TBCs had the highest value among the PS-PVD TBCs. Thus, the above phenomenon indicates that the scratch depth was getting shallower with the increasing Al thickness.

Therefore, it can be concluded that the various scratch depth depends on the hardness of the TBCs. The Al-modification process contributed to increasing hardness and it was also expected to improve the particle erosion resistance of PS-PVD TBCs.

The above assumptions shown in Fig. 5 a have been demonstrated by particle erosion testing, which was based on the testing standard GEAE-E50TF121. The erosion test specimen holder was in accordance with the GE drawing 4013240-525 (Fig. 5b). The weight losses of the as-sprayed and $20 \mu \mathrm{m}$ Al-modified TBCs were compared in Fig. $5 \mathrm{c}$ and the corresponding surface images after the particle erosion failure was seen in Fig. 5d. When the erodent exposure mass of grit reached $60 \mathrm{~g}$, the color of the bond coating was seen (Fig. 5). However, the $20 \mu \mathrm{m}$ Al-modified TBCs lost $90 \mathrm{~g}$ of grit before the appearance of the colored bond coating (Fig. 5). The above results showed that the Al-modified TBCs had a better erosion resistance than the as-sprayed PS-PVD 7YSZ TBCs.

\subsection{Comparison of thermal cycle performance}

Apart from the particle erosion resistance, the thermal cycle performance is an important parameter for the characterization of the TBCs representing frequent take-off and landing resistance ${ }^{30,32}$. The images of the as-sprayed and Al-modified PS-PVD with different water-quenching cycles were shown in Fig. 6. The $20 \mu \mathrm{m}$ Al-modified TBCs showed an optimal thermal cycle performance (Fig. 6a) compared to the other APS and EB-PVD TBCs ${ }^{33-48}$. In this work, the as-sprayed and Al-modified TBCs were compared, shown in Figs. 6b-i. The first spallation of the as-sprayed TBCs occurred in 162 cycles and after 198 cycles and the TBCs had been completely stripped from the surface of the substrate. With the $5 \mu \mathrm{m} \mathrm{Al}$ modified TBCs, the first spallation occurred in 100 cycles, and after 115 cycles, the TBCs separated from the substrate. Correspondingly, the $10 \mu \mathrm{m}$ Al-modified TBCs had first and final spallation occur in 131 and 162 cycles, respectively.

The above results show that the Al modification process had no positive effect on the thermal cycle performance for the PS-PVD 7YSZ TBCs. However, when the Al thickness increased to $20 \mu \mathrm{m}$, the Almodified TBCs had first spallations occur in 198 cycles. As the thermal cycle increased to 350 cycles, the TBCs were still not completely stripped from the substrate, they only showed an increase in the spallation 
area. Thus, the $20 \mu \mathrm{m}$ Al-modification was the best process for improving the thermal cycle performance of PS-PVD 7YSZ TBCs.

The results showed that the $20 \mu \mathrm{m}$ Al-modification was the optimal process for improving the thermal cycle performance of the PS-PVD 7YSZ TBCs. The surface microstructures of the $20 \mu \mathrm{m}$ Al-modified TBCs are shown in Fig. 7a. The gap between the cauliflower tops still can be seen and the magnified images indicated that many nanowires had been formed on the surface. Some cauliflower tops were connected by nanowires. The cross-sectional microstructure was shown in Fig. 7b, where the positions P1, P2, and P3 represent different areas. After the $20 \mu \mathrm{m}$ Al-modification, a dense overlay was formed on the top columnar coating. In the inner coating, the porous microstructure was still preserved. However, after 350 water-quenching cycles at $1100^{\circ} \mathrm{C}$, many cauliflower tops had been stripped from the surface and the grain size including nanowires had increased (Fig. 7c). The cross-sectional microstructures at different positions (P1, P2, and P3) were seen in Fig. 7d, and were becoming denser than the crosssection in Fig. 7b. The evolutionary process of the phase composition in the PS-PVD 7YSZ coating from the as-sprayed to the Al-modification to the water quenching state was shown in Fig. 7e. It indicated that there were three phases, $\mathrm{M}-\mathrm{ZrO}_{2}, \mathrm{~T}^{\prime}-\mathrm{ZrO}_{2}$, and C-ZrO${ }_{2}$, in the as-sprayed 7YSZ TBCs. After the $20 \mu \mathrm{m} \mathrm{Al}-$ modification, a new phase, a- $\mathrm{Al}_{2} \mathrm{O}_{3}$, was observed due to the in-situ synthesis between the $\mathrm{Al}$ and $\mathrm{ZrO}_{2}$ in the heated vacuum treatment ${ }^{29,49}$. After 350 water quenching cycles, the peaks of the $\mathrm{M}-\mathrm{ZrO}_{2}, \mathrm{~T}^{\prime}-\mathrm{ZrO}_{2}$, and $\mathrm{C}-\mathrm{ZrO}_{2}$ phases became shorter and wider because the small grain size had grown (Fig. $7 \mathrm{f}$ ). Based on the analysis of the $\mathrm{T}^{\prime}-\mathrm{ZrO}_{2}$ patterns, the grain sizes of the as-sprayed TBCs, the $20 \mu \mathrm{m}$ Al-modified TBCs, and the $20 \mu \mathrm{m}$ Al-modified TBCs after 350 thermal cycles were 21, 35, and $247 \mathrm{~nm}$, respectively. However, the a- $\mathrm{Al}_{2} \mathrm{O}_{3}$ peaks increased, which means the degree order of the grain structure had increased. Additionally, based on the analysis of the $\mathrm{T}^{\prime}-\mathrm{ZrO}_{2}$ patterns, the lattice stress of the as-sprayed TBCs, the $20 \mu \mathrm{m}$ Al-modified TBCs, and the $20 \mu \mathrm{m}$ Al-modified TBCs after 350 thermal cycles were $0.4,0.2$ and 0.41 $\mathrm{GPa}$, respectively (Fig. $7 \mathrm{~g}$ ). This means that the Al-modification process did not add lattice stress to the PS-PVD 7YSZ TBCs.

\section{Conclusions}

Considering the challenges of creating PS-PVD 7YSZ TBCs, this study sheds light on a new Almodification solution for particle erosion and thermal cycle. It was found that the Al-modification not only improved the particle erosion resistance but also increased the thermal cycle performance. Moreover, the aspiration is that the PS-PVD 7YSZ TBCs can be rapidly implemented to protect the high-temperature components in an aero-engine. Thus, the hope is that the current study may inspire further attempts to clear the application barriers. The Al-modification is a normal approach. And this technique can be extended to others structural coating such as environmental barrier coating, densified coating, etc.

\section{Declarations}

\section{Acknowledgments}


We would like to acknowledge the financial support from the National Natural Science Foundation of China (No. 51801034, No. 51771059), Guangdong Special Support Program (2019BT02C629),

Guangdong Academy of Sciences Program (No. 2020GDASYL-20200104030). and Guangzhou Technical Research Program (No. 201906010015).

\section{References}

1. Tomasz S et al (2012) The influence of quantity and distribution of cooling channels of turbine elements on level of stresses in the protective layer TBC and the efficiency of cooling. Computational Mater Sci 52:293-297

2. Enes A et al (2015) A review on superalloys and IN718 nickel-based INCONEL superalloy. Periodicals of Engine Nat Sci 3:15-27

3. Xia W (2020) et al. A review of composition evolution in Ni-based single crystal superalloys. J 44:7695 M S Technol

4. Sato A (2007) et al. Fifth generation Ni based single crystal superalloy with superior elevated temperature properties. Mater 2:19-25 S E Energy Sys

5. Bradshaw A (2013) et al. Development of hot corrosion resistant coatings for gas turbines burning biomass and waste derived fuel gases. Surf 216:8-22 C Technol

6. Chung J (2019) et al. Study on the effect of turbine inlet temperature and backpressure conditions on reduced turbine flow rate performance characteristics and correction method for automotive turbocharger. Energies 12:3934-3953

7. Chen Y (2020) et al. Measurements and understanding of the stiffness of an air plasma sprayed thermal barrier coating. Surf 394:125678-125687 C Technol

8. Zhang B (2019) et al. Failure and life evaluation of EB-PVD thermal barrier coatings using temperature-process-dependent model parameters. Corro 156:1-9 Sci

9. Satish T. et al. Development of a new TBC system for more efficient gas turbine engine application. Mater. Today: Proceedings 2016, 3:2725-2734.

10. Guo L (2020) et al. Microstructure modification of $\mathrm{Y}_{2} \mathrm{O}_{3}$ stabilized $\mathrm{ZrO}_{2}$ thermal barrier coatings by laser glazing and the effects on the hot corrosion resistance. J 9:232-242 A Ceram

11. Shi D (2019) et al. Cracking behaviors of EB-PVD thermal barrier coating under temperature gradient. Ceram 45:18518-18528 Int

12. Boissonnet $G$ (2020) Phase stability and thermal insulation of $Y S Z$ and erbia-yttria co-doped zirconia EB-PVD thermal barrier coating systems. Surf 389:125566-125572 C Technol

13. Vijay K (2016) et al. Progress update on failure mechanisms of advanced thermal barrier coatings: A review. Progress in Organic Coat 90:54-82

14. Amrinder M. et al. Recent developments in the designing of deposition of thermal barrier coatings A review. Mater. Today: Proceedings 2020, 26:1336-1342. 
15. Morumpalle S. et al. Development and analysis of thermal barrier coatings on gas turbine blades - A Review. Mater. Today: Proceedings 2018, 5:2746-2751.

16. Yang E (2015) et al. Epitaxial grain growth during 8YSZ splat formation on polycrystalline YSZ substrates by plasma spraying. Surf 274:37-43 C Technol

17. Markus M (2017) Correlation of splat morphologies with porosity and residual stress in plasmasprayed YSZ coatings. Surf 318:157-169 C Technol

18. Clabel $\mathrm{H}(2019)$ et al. Growth process and grain boundary defects in $\mathrm{Er}$ doped $\mathrm{BaTiO}_{3}$ processed by EB-PVD: A study by XRD, FTIR, SEM and AFM. App 493:982-993 S Sci

19. Xu Z (2015) et al. Morphology, bond strength and thermal cycling behavior of (Ni, Pt)Al/YSZ EB-PVD thermal barrier coatings. J 651:445-453 Alloys Comp

20. Deng Z (2018) et al. 7YSZ coating prepared by PS-PVD based on heterogeneous nucleation. Chinese $\mathrm{J}$ 31:820-825 Aeronautics

21. Zhang $Y$ (2020) et al. Impact of cathode loss on plasma characteristics, microstructures and properties of 7YSZ coatings in PS-PVD. Ceram 46:13307-13316 Int

22. Liu M (2019) Transport and deposition behaviors of vapor coating materials in plasma sprayphysical vapor deposition. App 486:80-92 S Sci

23. Zhang X (2016) et al. Gas-deposition mechanisms of 7YSZ coating based on plasma spray-physical vapor deposition. J 36:697-703 E C Soc

24. Mauer G (2015) et al. Novel opportunities for thermal spray by PS-PVD. Surf 268:52-57 C Technol

25. Stefan R (2017) et al. Investigation of the resistance of open-column-structured PS-PVD TBCs to erosive and high-temperature corrosive attack. Surf 324:222-235 C Technol

26. Michael P (2016) et al. Process-structure-property relations for the erosion durability of plasma spray-physical vapor deposition (PS-PVD) thermal barrier coatings. Surf 297:11-18 C Technol

27. Steinberg $L$ et al (2019) Erosion resistance of CMAS infiltrated sacrificial suspension sprayed alumina top layer on EB-PVD 7YSZ coating. Wear 438-439:203064-203079

28. Liu M et al (2018) Gaseous material capacity of open plasma jet in plasma spray-physical vapor deposition process. App Surf Sci 428:877-884

29. Liu M et al (2017) Evaporation of droplets in plasma spray-physical vapor deposition based on energy compensation between self-cooling and plasma heat transfer. J Thermal Spray Technol 26:1641-1650

30. Zhang X (2019) et al. Structural evolution of Al-modified PS-PVD 7YSZ TBCs in thermal cycling. Ceram 45:7560-7567 Int

31. Cernuschi $F$ (2011) et al. Solid particle erosion of thermal spray and physical vapour deposition thermal barrier coatings. Wear 271:2909-2918

32. Gao L (2015) et al. Microstructure, thermal conductivity and thermal cycling behavior of thermal barrier coatings prepared by plasma spray physical vapor deposition. Surf 276:424-430 C Technol 
33. Nusair Khan A (2003) et al. Behavior of air plasma sprayed thermal barrier coatings, subject to intense thermal cycling. Surf 166:37-43 C Technol

34. Ke P (2005) et al. Study on thermal barrier coatings deposited by detonation gun spraying. Surf 200:2271-2276 C Technol

35. Ke $\mathrm{P}$ (2006) et al. Progressive damage during thermal shock cycling of $D$-gun sprayed thermal barrier coatings with hollow spherical $\mathrm{ZrO}_{2}-8 \mathrm{Y}_{2} \mathrm{O}_{3}$. Mater 435-436:228-236 S E A .

36. Nusair Khan A (2007) et al. Thermal cyclic behavior of air plasma sprayed thermal barrier coatings sprayed on stainless steel substrates. Surf 201:4653-4658 C Technol

37. Das $S$ (2009) et al. Thermal cyclic behavior of glass-ceramic bonded thermal barrier coating on nimonic alloy substrate. Ceram 35:2123-2129 Int

38. Yang D (2017) et al. Thermal shock resistance of bimodal structured thermal barrier coatings by atmospheric plasma spraying using nanostructured partially stabilized zirconia. Surf 315:9-16 C Technol

39. Ashofteh A (2018) et al. Thermal shock behavior of multilayer and functionally graded micro- and nano-structured topcoat APS TBCs. Ceram 44:1951-1963 Int

40. Li M (2007) et al. Thermal shock behavior of EB-PVD thermal barrier coatings. Surf 201:7387-7391 C Technol

41. Mineaki $\mathrm{M}(2009)$ et al. Thermal conductivity and thermal cycle life of $\mathrm{La}_{2} \mathrm{O}_{3}$ and $\mathrm{HfO}_{2}$ doped $\mathrm{ZrO}_{2}-$ $\mathrm{Y}_{2} \mathrm{O}_{3}$ coatings produced by EB-PVD. Surf 203:2835-2840 C Technol

42. Xu Z (2015) et al. Thermal cycling behavior of EB-PVD TBCs on CVD platinum modified aluminide coatings. J 637:226-233 Alloys Comp

43. Shen Z (2019) et al. LZC/YSZ double layer coatings: EB-PVD, microstructure and thermal cycling life. Surf Coat Technol 367:86-90

44. Uwe S (2020) et al. Effect of processing and interface on the durability of single and bilayer 7YSZ / gadolinium zirconate EB-PVD thermal barrier coatings. Surf 381:125107-125116 C Technol

45. Zhang $X$ (2018) et al. Mechanisms governing the thermal shock and tensile fracture of PS-PVD 7YSZ TBC. Ceram 44:3973-3980 Int

46. Lin R (2019) et al. Investigation of TGO stress in thermally cycled plasma-spray physical vapor deposition and electron-beam physical vapor deposition thermal barrier coatings via photoluminescence spectroscopy. Surf 378:125047-125054 C Technol

47. Naraparaju $\mathrm{R}$ et al (2018) EB-PVD alumina $\left(\mathrm{Al}_{2} \mathrm{O}_{3}\right)$ as a top coat on 7YSZ TBCs against CMAS/VA infiltration: deposition and reaction mechanisms. J Eur Ceram Soc 38:3333-3346

48. Leushake $U$ et al (1997) Microstructure and phase stability of EB-PVD alumina and alumina/zirconia for thermal barrier coating applications. Surf Coat Technol 94:131-136

49. Zhang $X$ (2014) et al. In situ synthesis of a-alumina layer at top yttrium-stabilized zirconia thermal barrier coatings for oxygen barrier. Ceram 40:12703-12708 Int 


\section{Figures}
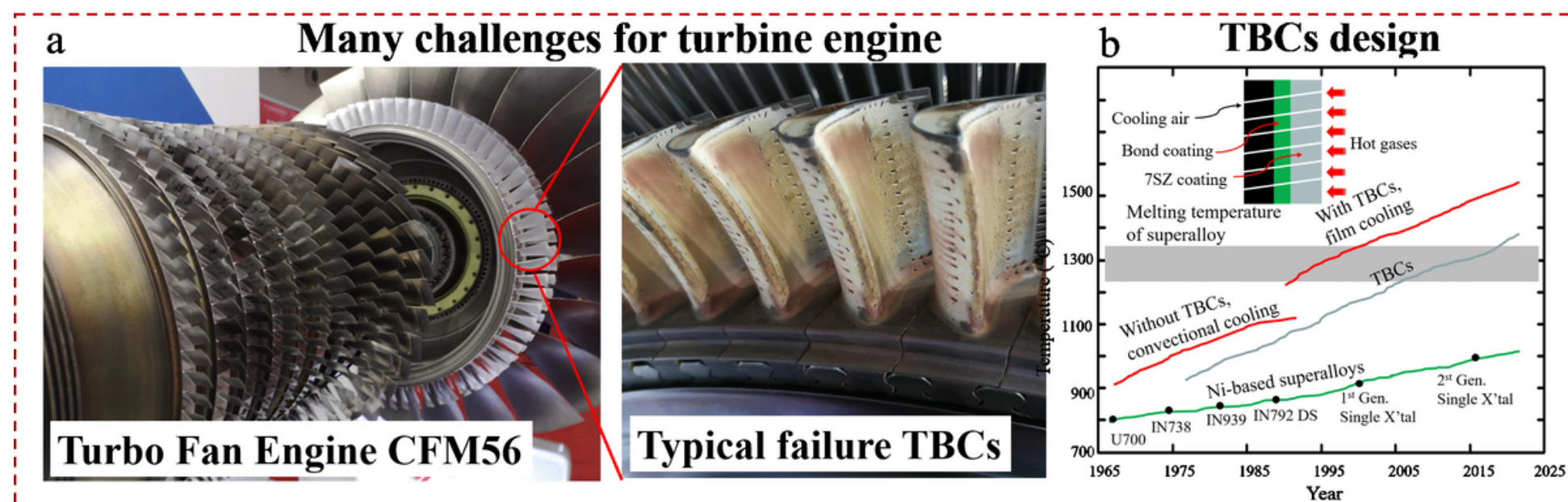

\section{c APS TBCs}

$\sqrt{ }$ High efficiency

$\sqrt{ }$ Low cost

$\sqrt{ }$ Low thermal conductivity

$\times$ Low stain tolerance

$\times$ Low bond strength

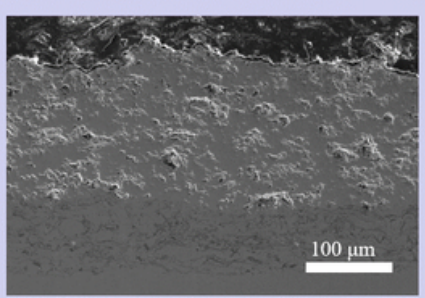

PS-PVD TBCs

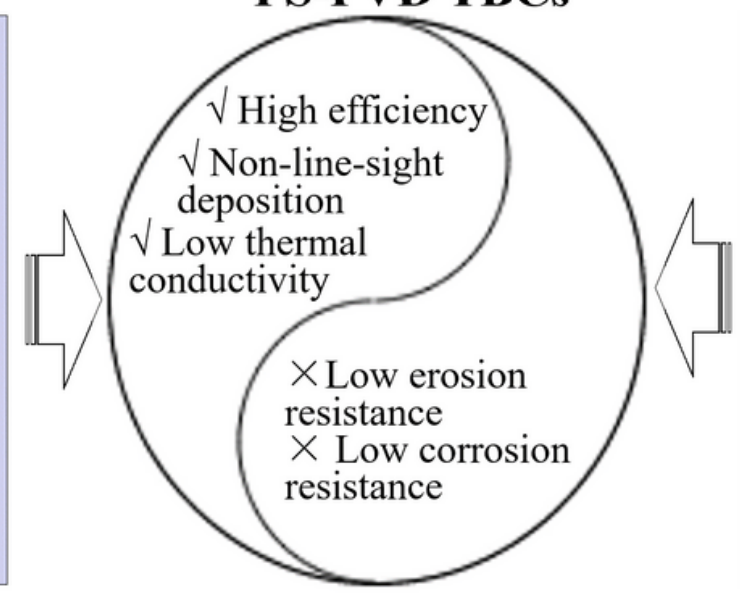

EB-PVD TBCs

$\sqrt{ }$ Good stain tolerance

$\sqrt{ }$ High bond strength

$\times$ Low efficiency

$\times$ High cost

$\times$ High thermal conductivity

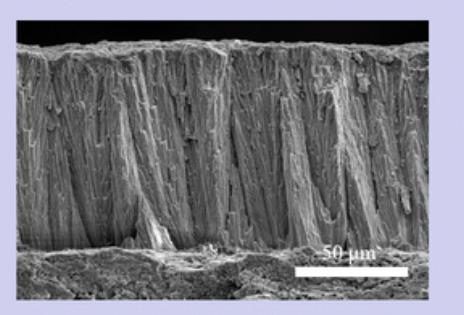

Figure 1

Challenges of TBCs used in aero-engines. (a) Failure of TBCs after long service life, which faces many environmental challenges. (b) Constant progress of the aero-engine. (c) Advantages and disadvantages of the APS, EB-PVD, and PS-PVD processes. 


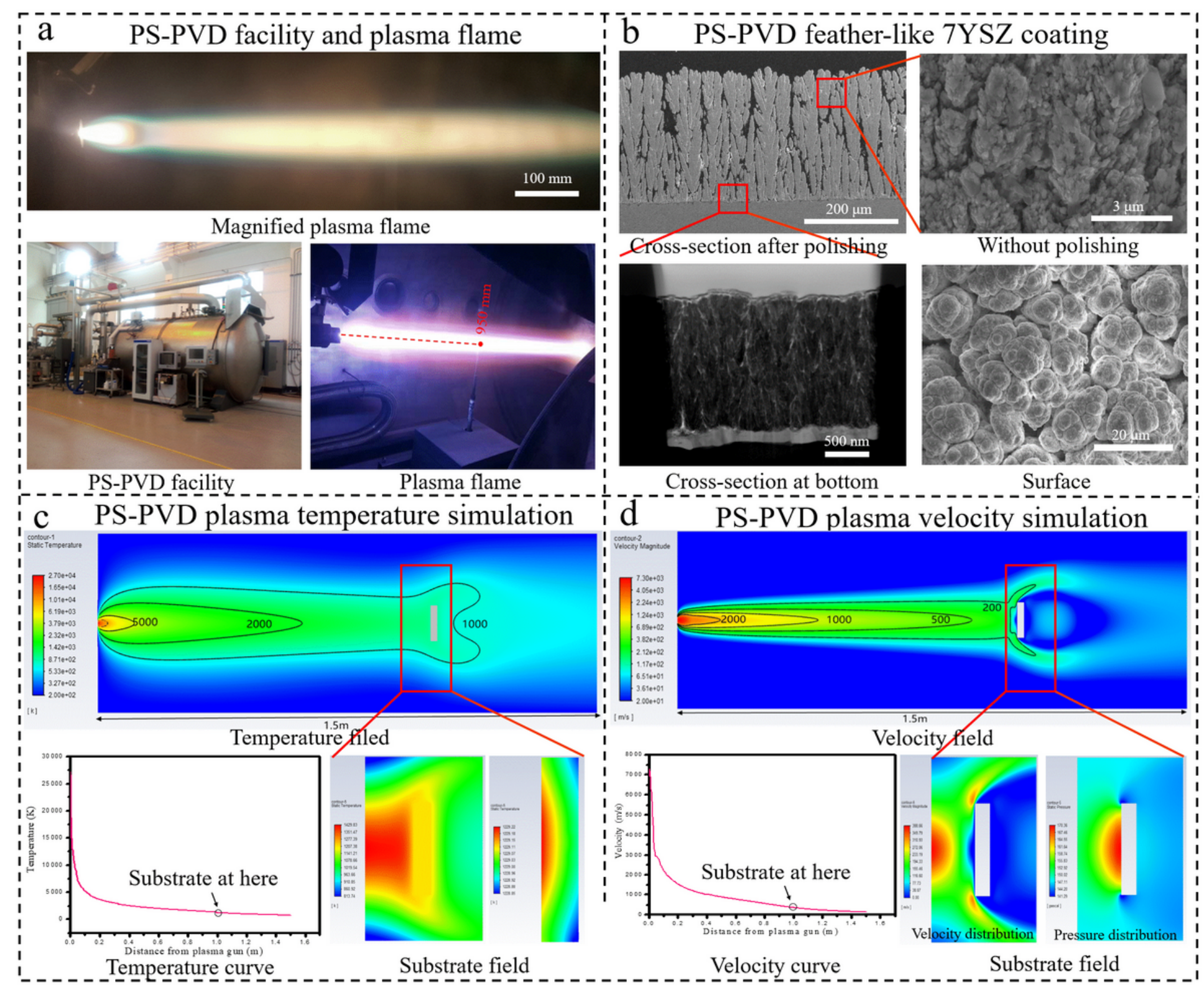

Figure 2

The PS-PVD facility, the 7YSZ coating, and the plasma flow simulation. (a) PS-PVD facility and plasma flame. (b) Feather-like columnar 7YSZ TBCs prepared by PS-PVD. (c) Plasma flow simulation showing the temperature gradient. (d) Plasma flow simulation showing the velocity gradient. 




Figure 3

The different environmental factors affecting TBCs and Al-modification schematic diagram. (a) TBCs in high temperature, with particle erosion, and CMAS corrosion. (b) Schematic of Al-modified PS-PVD feather-like columnar 7YSZ TBCs, showing an a-Al203 overlay on the column surface. (c) SEM images of the cross-sectional microstructure of the Al-modified 7YSZ coating with different Al film thicknesses (5, 10, and $20 \mu \mathrm{m}$ ). (d) TEM analysis of $5 \mu \mathrm{m}$ Al-modified TBCs including HAADF (High angle Annular Dark Field) image and $\mathrm{Al}, \mathrm{O}$ and $\mathrm{Zr}$ mappings. 


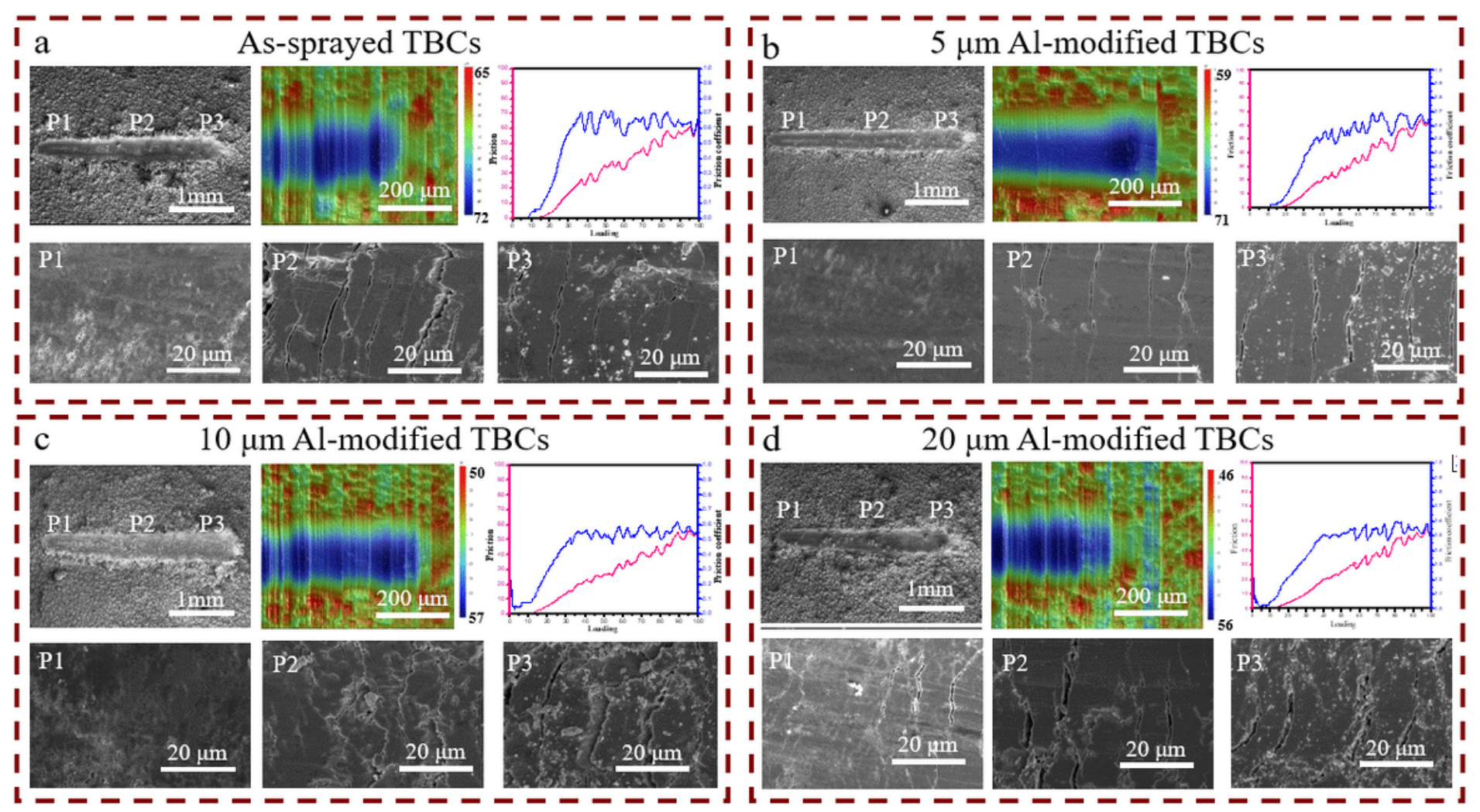

Figure 4

Scratch test comparison of TBCs. (a) As-sprayed TBCs showing a scratch depth of $72 \mu \mathrm{m}$, a profile microstructure, and curves for loading, friction, and the friction coefficient. (b) $5 \mu \mathrm{m}$ Al-modified TBCs showing a scratch depth of $71 \mu \mathrm{m}$, a profile microstructure, and curves for loading, friction, and a friction coefficient. (c) $10 \mu \mathrm{m}$ Al-modified TBCs showing a scratch depth of $57 \mu \mathrm{m}$, a profile microstructure, and curves for loading, friction, and a friction coefficient. (d) $20 \mu \mathrm{m}$ Al-modified TBCs showing a scratch depth of $56 \mu \mathrm{m}$, a profile microstructure, and curves for loading, friction, and friction coefficient. 


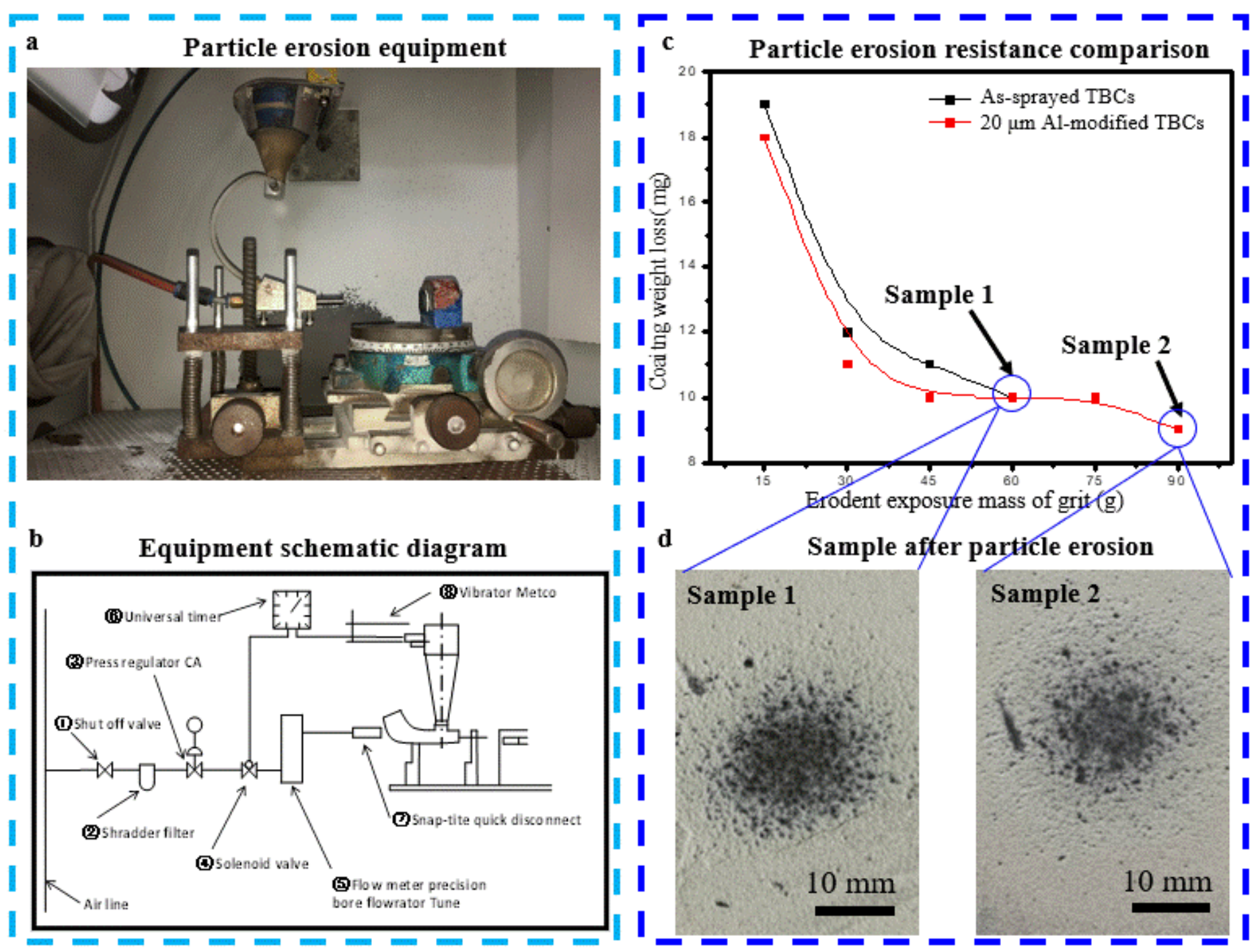

Figure 5

Particle erosion comparison of the as-sprayed and Al-modified TBCs. (a) Particle erosion equipment. (b) Schematic diagram of figure A. (c) Erodent exposure of grit between the as-sprayed and $20 \mu \mathrm{m}$ Almodified TBCs. (d) Sample morphology after particle erosion testing, corresponding to samples 1 and 2. 


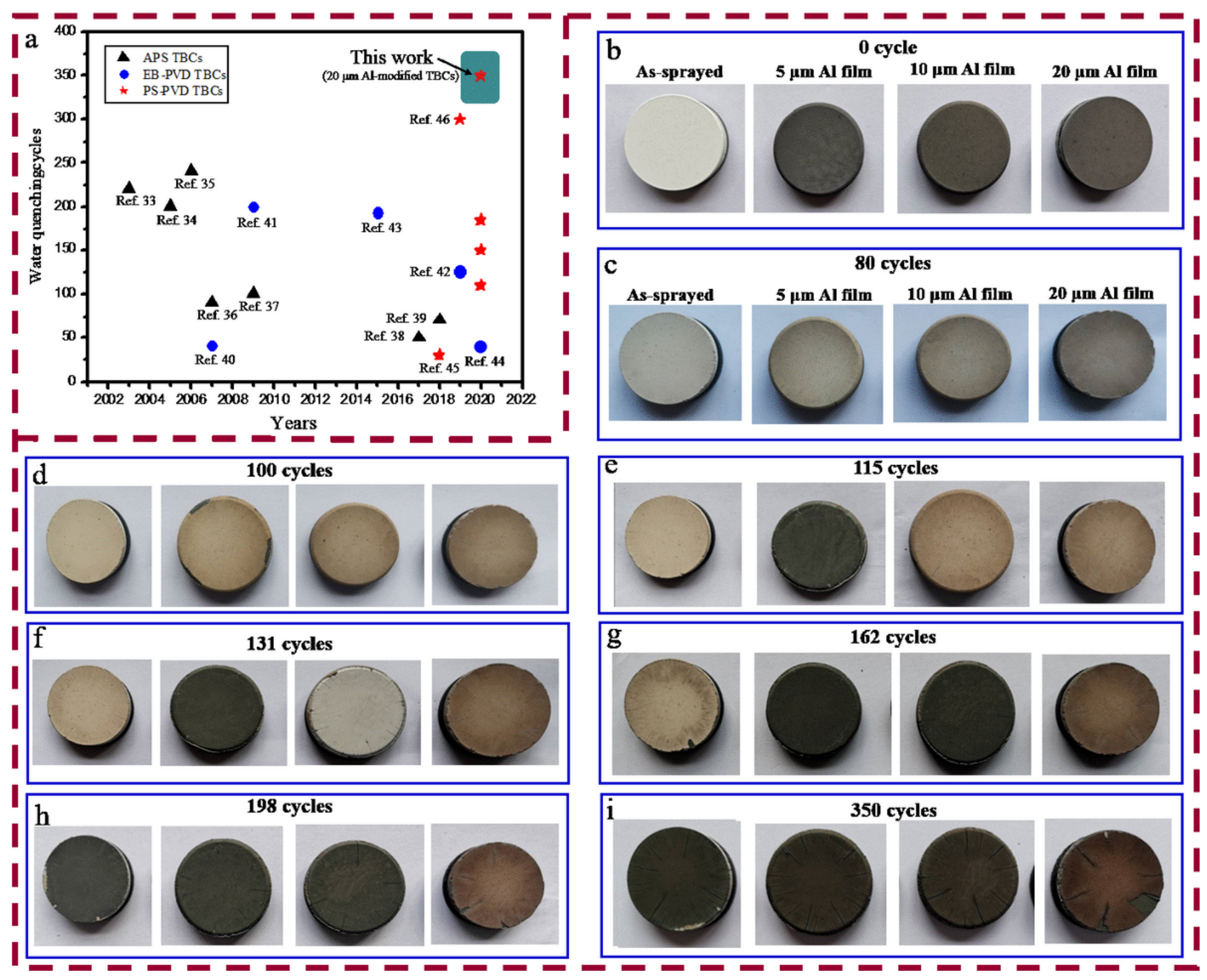

Figure 6

Water quenching test comparison between the as-sprayed and Al-modified TBCs. (a) Thermal cycle comparison between APS, EB-PVD, and PS-PVD TBCs. (b) The four samples including one as-sprayed sample (left) and three Al-modified samples (right, 5, 10, and $20 \mu \mathrm{m}$ thick Al film modifications). (c) After 80 cycles, the samples showed no apparent spallation. (d) After 100 cycles, the $5 \mu \mathrm{m}$ Al-modified samples showing slight edge spallation. (e) After 115 cycles, the $5 \mu \mathrm{m}$ Al-modified samples showed complete spallation. (f) After 131 cycles, the $10 \mu \mathrm{m}$ Al-modified samples showed slight spallation. (g) After 162 cycles, the as-sprayed samples showed slight edge spallation. (h) After 198 cycles, the samples showed complete spallation. (i) After 350 cycles, the samples showed edge spallation. 

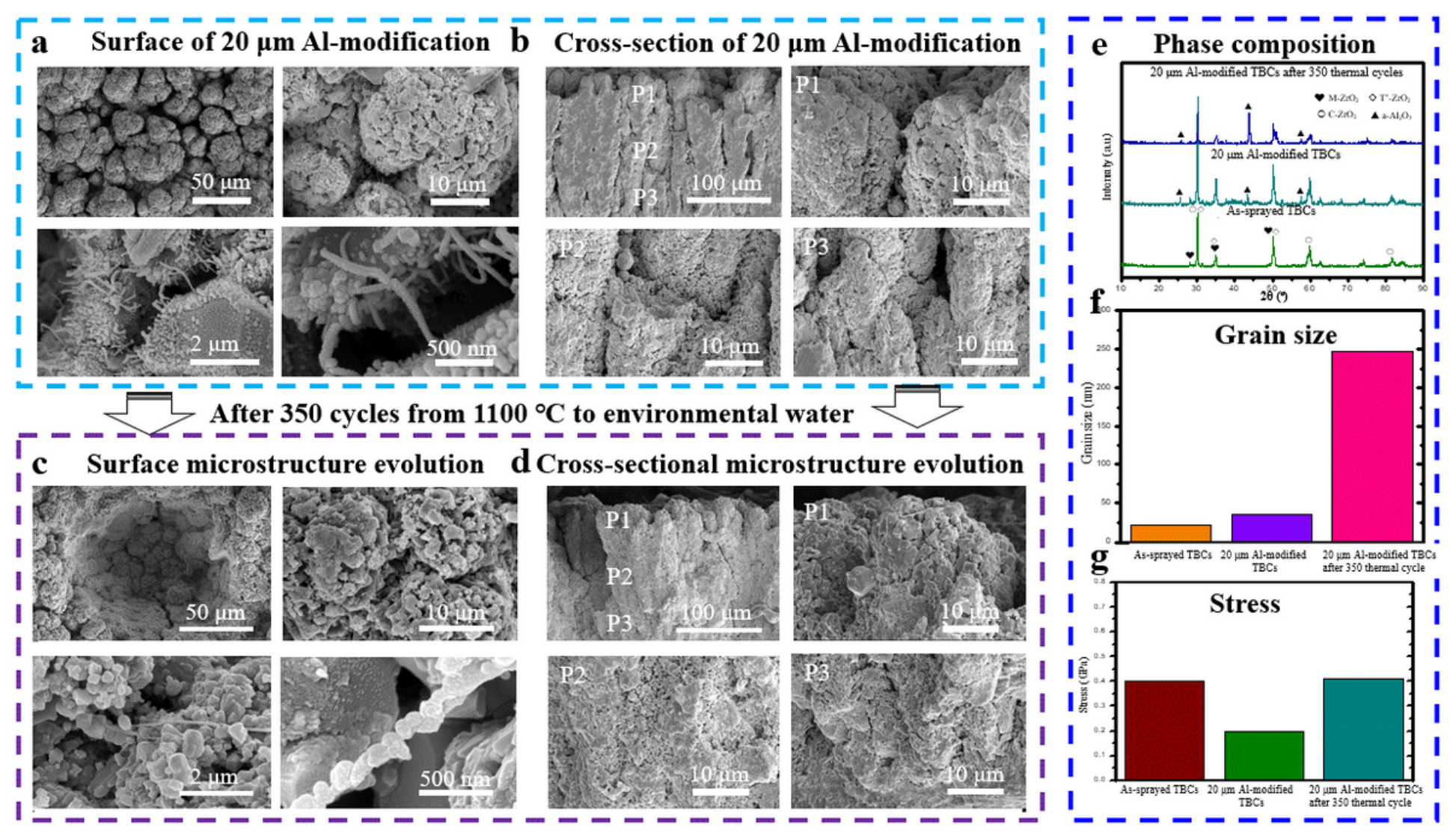

Figure 7

Surface evolution of the $20 \mu \mathrm{m}$ Al-modified TBCs before and after thermal quenching. (a) The surface microstructures before water quenching, showing the nanowires on cauliflower tops. (b) The crosssectional microstructure before water quenching showing different densities from top to bottom. (c) The surface microstructure after 350 cycles indicating the spallation of the cauliflower tops. (d) Crosssectional microstructure after 350 cycles showing vertical crack and grain size grown. (e) Phase compositions of the as-sprayed TBCs (M-ZrO2, T'-ZrO2, C-ZrO2), the Al-modified TBCs (new a-Al2O3 phase generation) and the Al-modified TBCs (a-Al2O3, M-ZrO2, T'-ZrO2, C-ZrO2) after 350 cycles. (f) The corresponding surface grain sizes $(21,35$, and $247 \mathrm{~nm})$ of the three types of TBCs. $(\mathrm{g})$ The corresponding stresses $(0.4,0.2$, and $0.41 \mathrm{GPa})$ of the three types TBCs. 